\title{
The Need for National Registry
}

\author{
Yoga Yuniadi
}

\section{"Ocience tells us what we can do: Guidelines vell us what we should do: ORegistries tell us what we are actually doing. "}

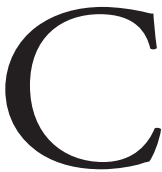

urrently medical outcomes research has generally been conducted with 3 sources of data: randomized clinical trials, administrative claims databases, and data registries. Each of these data sources has a unique set of applications, data quality issues, and requirements. ${ }^{1}$ In United State, clinical trials is part of the pharmaceutical and device pre-approval process thus it has highly regulated requirements for source document verification. ${ }^{2}$ In contrast, quality control of administrative data is primarily limited to fields directly related to claims adjudication. Thus, administrative claims data are significantly limited for the purposes of performing healthcare research. ${ }^{3}$ Like administrative claims data, registries are nonrandomized, observational datasets that can be generalized to real-world practice, depending on the representativeness of participants and the completeness of enrollment. ${ }^{4}$ However, as with the data collected in randomized clinical trials, registries include detailed clinical data using standardized data definitions.

It always embarrass when lacks of national data lead us to present the epidemiology data of other countries. Obviously, other country data is not accurately describe

\section{Alamat Korespondensi}

Dr. dr. Yoga Yuniadi, SpJP. Divisi Aritmia, Departemen Kardiologi dan Kedokteran Vaskular, FKUI dan Pusat Jantung Nasional Harapan Kita, Jakarta. E-mail: yogayI36@gmail.com our real situation. When talking about specific clinical situation the availability of Indonesian national data is always zero. Then who should be responsible to do national survey on detail and specific clinical condition? Dr. Fadillah Supari, the past Ministry of Health of Republic Indonesia is among the first who encourage national registry in national health database. Her first registry on basic health data is continued by her predecessors. Currently, newest basic national health data are resulted from national survey conducted on 2013. However when we try to find special data, for example detail cardiovascular diseases, it will end up with disappointment as national data did not go further into specific area.

National data on cardiovascular (CV) disease are extremely important. The goal is that the national CV health registries shall provide current, reliable and secure information about the population's $\mathrm{CV}$ health and the quality of healthcare. This includes information about disease incidence, unexpected changes in incidence patterns such as during an epidemic, and knowledge about risk factors and causes of disease. To achieve this, CV health registries must provide accurate and complete information in real time. Cardiovascular health registries should be relevant, useful, accessible, of high quality, with strong privacy protection, and able to provide ongoing analysis and research. For special interest on specific data it would be hard to lay on government role. Professional society must take initiative to collect particular data.

We can learn from European Society of Cardiology who decided to make an initiative action on $\mathrm{CV}$ diseases registries so called EurObservational Research Program. They divide the registries into four 
categories: (1) General registry is intended to provide epidemiological data and reports on application of clinical practice guidelines recommendations, (2) Sentinel registry to assess the impact of interventional procedures and imaging techniques, (3) Special registry to assess epidemiology and management of rarer conditions as arising critical issues in terms of public health (severity of diseases, stringent clinical needs and costs), (4) Prevention registry to assess cardiovascular risk factors epidemiology and prevention measures.
Those registries have been scheduled in detail for period of more than five years (Figure 1). ${ }^{5}$

The contribution of cardiology subspecialty society such as Indonesian Society of Interventional Cardiologist (ISIC), Indonesian Heart Rhythm Society (InaHRS) and Indonesian Society of Echocardiography (InaEcho) are essential as they have good communication to facilitate data collection in specific area and build effective research collaboration.

National CV registries have to be organized care-

EURObservational Research Programme - EORP

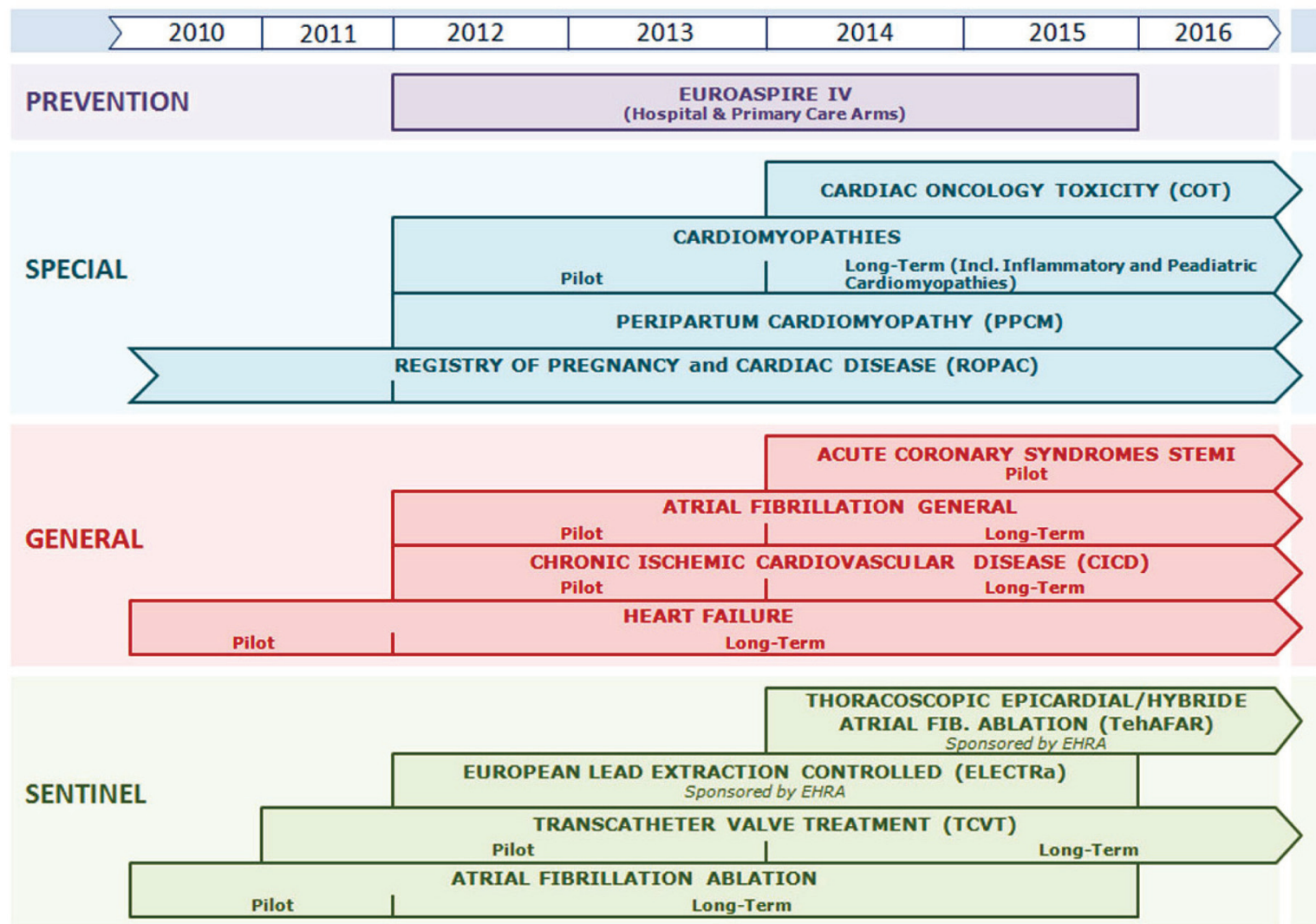

Figure 1. Clearly shows that acute coronary syndrome, atrial fibrillation, chronic ischemic cardiovascular disease and heart failure are considered as general CV problem that its data need to be updated. Some new intervention modalities such as mini surgical atrial fibrillation ablation, lead extraction program, transcatheter valve replacement and atrial fibrillation ablation are among area that still need additional data for future development. In our country of Indonesia those topics would be much different. Prevention registry need to elaborate the influence of carbohydrate rich food on $\mathrm{CV}$ disease in our specific population, registry on obesity among urban and rural population. Special registry can be done in area of rheumatic heart disease, rheumatic fever, myocarditis related to tropical infectious disease, Brudaga syndrome, peripartal cardiomyopathy and sudden cardiac death. General survey on acute coronary syndrome, atrial fibrillation and heart failure are also important in Indonesia. Primary percutaneous coronary intervention in STEMI patient, atrial fibrillation ablation, left atrial appendage closure are among area of interest in sentinel registry. 
fully. One main committee that is responsible for the entire program, namely The Oversight Committee consist of national key persons. Below the oversight committee are two committees that run each study: Executive Committee and Steering Committee. The coordinating team manages all data collection which is responsible for providing organizational support to the centers, management of databases, and liaising with statistical centers selected by the Executive Committee of each Survey/Registry, in agreement with the Oversight Committee. Data is centralized at PERKI House. The main role of the team is to coordinate the project, provide support to the Committees, National Coordinators and participating centers and ensure that the methodological concepts of the survey are adhered to. This team has to assure the quality control and continuity necessary to ensure that projects are completed on time and within budget.

Funding is one of essential requirement to perform national survey. Considering the importance of accurate $\mathrm{CV}$ registry as a basis to develop effective and efficient government program in reducing morbidity and mortality of CV disease, official funding from Ministry of Health or Ministry of Research and Technology can be expected. Other sources of fund are research grants either from industry or government.

As the uses of registry data expand, the need for data validation increases. Enhanced data validation is necessary to meet stakeholder requirements such as those implemented by insurance payers for payfor-performance, consumer coalitions for direct-toconsumer reporting, and government agencies such as BPOM for post-approval surveillance using registry data. Such initiatives often carry implicit or explicit consequences for patients, providers, and manufacturers, further highlighting the need for accuracy. ${ }^{1}$

In conclusion, national CV registries is essential. Indonesian Heart Association (IHA) must take initiative to start the registries hand in hand with government and industries. A solid team based at Perki (IHA) house coordinates all local team from centers all over Indonesia.

\section{References}

1. Messenger JC, Ho KK, Young CH, Slattery LE, Draoui JC, Curtis JP, Dehmer GJ, Grover FL, Mirro MJ, Reynolds MR, Rokos IC, Spertus JA, Wang TY, Winston SA, Rumsfeld JS, Masoudi FA. The National Cardiovascular Data Registry (NCDR) Data Quality Brief: the NCDR Data Quality Program in 2012. J Am Coll Cardiol. 2012;60(16):1484-1488.

2. Jollis JG, Ancukiewicz M, DeLong ER, Pryor DB, Muhlbaier LH, Mark DB. Discordance of databases designed for claims payment versus clinical information systems. Implications for outcomes research. Ann Intern Med. 1993;119(8):844-850.

3. Shahian DM, Silverstein T, Lovett AF, Wolf RE, Normand SL. Comparison of clinical and administrative data sources for hospital coronary artery bypass graft surgery report cards. Circulation. 2007;115(12):1518-1527.

4. Gliklich R, Campion FX. Patient registries. MGMA Connex. 2010;10(1):15-17.

5. Cardiology ESo. EURObservational Research Programme. The new programme of surveys and registries Available at: http:// www.escardio.org/guidelines-surveys/eorp/Pages/welcome.aspx. Accessed 12 January, 2014. 